\title{
Observations of Wintertime U.S. West Coast Precipitating Systems with W-Band Satellite Radar and Other Spaceborne Instruments
}

\author{
SERGEY Y. MATROSOV \\ Cooperative Institute for Research in Environmental Sciences, University of Colorado, and NOAA/Earth System \\ Research Laboratory, Boulder, Colorado
}

(Manuscript received 6 November 2010, in final form 24 June 2011)

\begin{abstract}
The potential of CloudSat W-band radar for observing wintertime storms affecting the West Coast of North America is evaluated. Storms having high hydrological impact often result from landfalls of "atmospheric rivers" ("ARs"), which are the narrow elongated regions of water vapor transport from the tropics. CloudSat measurements are used for retrievals of rain rate $R$ and cloud ice water path (IWP) along the satellite ground track over ocean and land. These retrievals present quasi-instantaneous vertical cross sections of precipitating systems with high-resolution information about hydrometeors. This information is valuable in coastal areas with complex terrain where observations with existing instrumentation, including ground-based radars, are limited. CloudSat reflectivity enhancements [i.e., bright band (BB)] present a way to estimate freezing levels, indicating transitions between rainfall and snowfall. CloudSat estimates of these levels were validated using data from radiosonde soundings and compared to model and microwave sounder data. Comparisons of CloudSat retrievals of rain rates with estimates from ground-based radars in the areas where measurements from these radars were available indicated an agreement within retrieval uncertainties, which were around $50 \%$. The utility of CloudSat was illustrated for case studies of pronounced AR events at landfall and over ocean. Initial analysis of CloudSat crossings of ARs during the 2006/07 season were used for rainfall regime prevalence assessment. It indicated that stratiform rain, which often had BB features, warm rain, and mixed rain were observed with about $26 \%, 24 \%$, and $50 \%$ frequency. Stratiform regions generally had higher rain rates. Significant correlation $(\sim 0.72)$ between mean values of IWP and rain rate was observed for stratiform rainfall.
\end{abstract}

\section{Introduction}

For a number of years, the National Oceanic and Atmospheric Administration (NOAA) Earth System Research Laboratory (ESRL), in collaboration with other laboratories and agencies, has been conducting Hydrometeorological Test Bed (HMT) studies in California and the Pacific Northwest. These studies include detailed observations of precipitating systems, which move from the Pacific Ocean inland and impact the West Coast of the United States. The observations are conducted using a wide array of ground-based sites where different types of meteorological and hydrological measurements are performed with a variety of direct and remote sensors, including vertically profiling radars (http://hmt.noaa.gov).

Wintertime landfalling moisture-laden Pacific storms, which can produce heavy rainfall and cause widespread

Corresponding author address: Sergey Y. Matrosov, R/PSD2, 325 Broadway, Boulder, CO 80305.

E-mail: sergey.matrosov@noaa.gov flooding, have a significant societal impact and are a subject for HMT studies. Such storms are often associated with the atmospheric river (AR) events, which are manifested by long and relatively narrow bands of enhanced water vapor amount stretching from the tropical regions to the West Coast of North America (e.g., Zhu and Newell 1998; Ralph et al. 2004, 2006; Neiman et al. 2008b). These atmospheric phenomena are responsible for much of the meridional water vapor transport. Usually a $20-\mathrm{mm}$ threshold for integrated water vapor (IWV) amount is used to determine AR systems.

In spite of their importance to the global water cycle and wintertime coastal weather conditions, AR-associated landfalling storms are still not adequately observed. IWV values are generally available from satellite passive microwave measurements over water surfaces and from satellite- and ground-based measurements using global positioning system (GPS) signals (e.g., Neiman et al. 2008a). Large-scale vertically resolved information on clouds and precipitation is generally lacking, although ground-based radars provide some measurements of 
atmospheric hydrometeors in the vicinity of surface radar sites and aircraft dropsonde observations provided valuable information on water vapor flux (Ralph et al. 2005).

The research polar-orbiting satellite CloudSat carrying the W-band ( $\sim 94 \mathrm{GHz})$ nadir-pointing cloud-profiling radar (CPR) on board (e.g., Tanelli et al. 2008) provides some new opportunities for observing storms and atmospheric river phenomena. Besides retrieving cloud parameters, which is the main objective of this satellite, the CPR reflectivity factor (or simply "reflectivity," $Z_{e}$ ) measurements could be used for precipitation retrievals as well using reflectivity-gradient attenuation-based approaches (e.g., Matrosov et al. 2008) or, in cases of observations over water surfaces, using path-integrated attenuation (PIA) approaches (e.g., Haynes et al. 2009). Due to the nadir-pointing geometry of the measurements, the CPR lacks a horizontal spatial coverage, but it is able to provide quasi-instantaneous high-spatial-resolution vertical cross sections of clouds and precipitation, which could be a valuable piece of information not available with other satellite- and/or ground-based instruments.

The utility of CPR-based retrievals for stratiform summertime precipitating systems observed over relatively flat land surfaces has been demonstrated for the retrieval method that uses estimates of W-band radar signal attenuation for assessing rain rate (Matrosov 2010a). In warmer systems with freezing levels that are generally higher than 2.5-3 km above the ground, total attenuation effects of rainfall are usually quite strong and CPR-based retrievals produce sensible results. CloudSat retrievals of colder rainfall over highly variable terrain present more challenges because of possible contamination from ground returns and thinner rainfall layer.

The purpose of this article is to illustrate and assess the utility of CloudSat measurements for providing information about the AR systems that produce wintertime landfalling Pacific storms in the West Coast domain of studies in the framework of HMT and other related research projects such as CalWater. One objective of such projects is to improve model representations of ARs offshore through specialized observations. It is suggested that CloudSat observations can provide valuable insight in the AR system structure that is not currently available with other remote sensors. In particular, these observations can address such important issues as assessment of AR rainfall regime prevalence and water substance partitioning in stratiform rainfall.

\section{CloudSat-based approaches}

The CPR approaches used in this study for retrievals of parameters of precipitating cloud systems are described in detail by Matrosov et al. (2008). These retrievals are performed simultaneously and independently for the liquid hydrometeor layer, where estimates of layer mean rainfall are obtained, and the layer containing predominantly ice phase hydrometeors, where ice water content (IWC) and its vertical integral-ice water path (IWP) - are estimated. As a result, parameters characterizing the total cloud ice mass and the resultant rainfall are retrieved for the same vertical atmospheric column with horizontal resolutions of about $1.4 \mathrm{~km}$ across the satellite track and $1.8 \mathrm{~km}$ along the track (Tanelli et al. 2008). Compared to the previous version of CPR rain retrieval method over water surfaces, an important modification of the retrievals in this study is that the absorption by liquid water clouds is estimated not using a priory values of liquid water path (LWP) but rather LWP estimates from the Advanced Microwave Scanning Radiometer for Earth Observing System (EOS) (AMSR-E) aboard the Aqua satellite, which flies in the A-train satellite formation with CloudSat. These estimates come from the retrievals that use observationally constrained databases of hydrometeor and meteorological parameters profiles (Kummerow et al. 2011) and are included in the CloudSat 2C Precipitation Column algorithm (2C-PRECIP-COLUMN) for resolution pixels that are closest to the CPR footprint.

The separation between hydrometeor thermodynamic phases (i.e., between ice and liquid water) is achieved by means of the radar brightband (BB) features, which are often identifiable in CloudSat measurements in stratiform precipitation. These features are caused by some initial increase in observed reflectivity when snow particles begin to melt, followed by a rapid reflectivity decrease caused by attenuation further in the melting and liquid hydrometeor layers. As modeling and high-resolution radar data indicate (e.g., Sassen et al. 2007), in stratiform precipitation the thickness of this layer is usually $0.4-0.6 \mathrm{~km}$.

The BB features in CloudSat reflectivity measurements are sought within $\pm 1.2 \mathrm{~km}$ of the freezing level as predicted by the European Centre for Medium-Range Weather Forecast (ECMWF) model data. These data along the CloudSat trajectory are contained in the ECMWF auxiliary data (ECMWF-AUX) files supplied by the CloudSat data center. The model temperature data and shapes of CPR profiles are also used to identify areas of "warm" rainfall, which is formed through interaction between cloud, drizzle, and rain drops, as opposed to stratiform BB rains (i.e., "cold" rains) for which snowflake melting is the main precipitation formation process. Warm rain tops are often observed below the freezing level, thus no BB features are available in observations.

Since the vertical profiles of nonattenuated reflectivity in stratiform rain vary relatively little (e.g., Matrosov 2010b) and W-band non-Rayleigh scattering effects reduce 


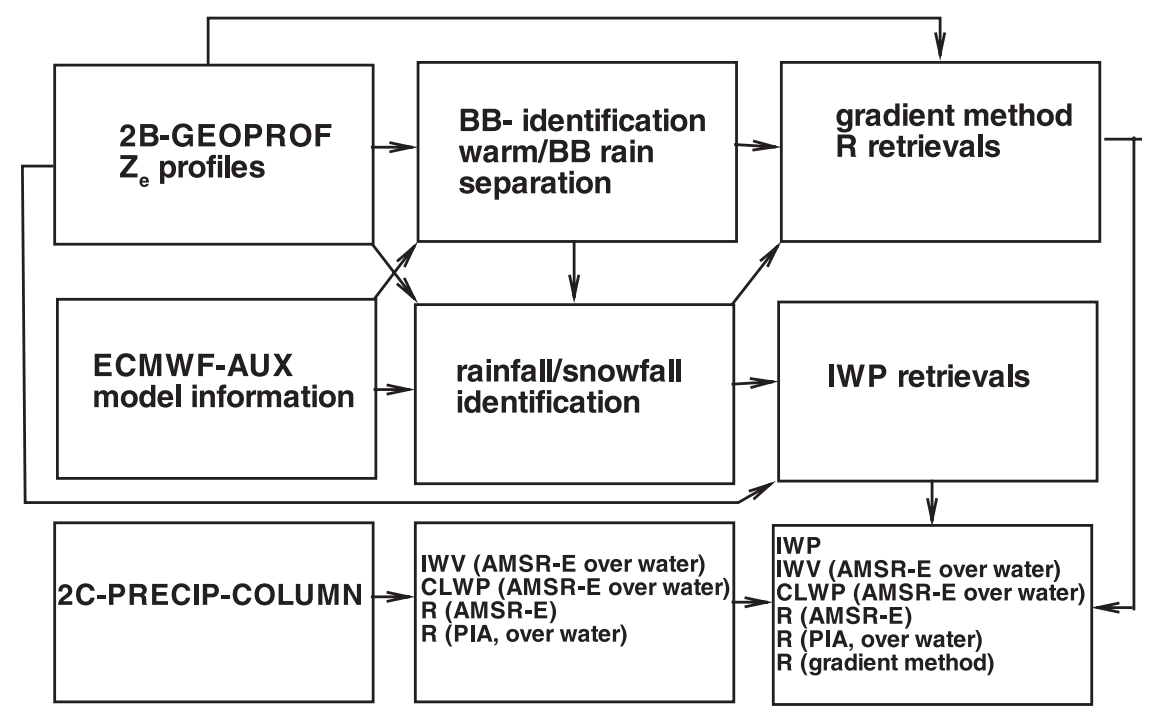

FIG. 1. A schematic diagram of the retrievals. Gradient method rainfall retrievals, retrievals of IWP, PIA-based rainfall retrievals, and AMSR-E-based retrievals are described in Matrosov et al. (2008), Matrosov and Heymsfield (2008), Haynes et al. (2009), and Kummerow et al. (2011).

this variability even further, the vertical gradients of observed CloudSat reflectivities in the liquid hydrometeor layer are used to estimate the attenuation coefficient. This coefficient is estimated at different heights within the rainfall layer and then it is related to rain rate after accounting for attenuation in atmospheric gases and liquid water clouds and multiple scattering effects in rainfall. To minimize contaminations of radar returns by the melting layer and the ground, measurements from three resolution gates immediately above the ground and three gates below the melting layer are usually not used for rainfall retrievals. The vertical gradient retrieval method does not rely on surface returns and can be used for measurements above both water and land surfaces. The mean layer rain-rate value is then calculated from the vertical profile of rain rates. The notation $R$ is used for this value.

For the same atmospheric column where rainfall is retrieved, the vertical profile of IWC and IWP are estimated using absolute measurements of reflectivity (Matrosov and Heymsfield 2008). The radar attenuation in the ice phase is significantly less than that in the liquid phase. This attenuation is balanced out approximately by modest enhancement because of multiple scattering that exists in CloudSat measurements in snow and thick ice clouds (Matrosov and Battaglia 2009). Because of this balancing effect, the radar reflectivity $Z_{e}$ based estimators are generally suitable for CloudSat retrievals of IWC in ice clouds using relations specifically tuned for W-band radar measurements.

A schematic diagram of the retrievals used in this study is shown in Fig. 1. The 2B Geometrical Profiling
(2B-GEOPROF) product contains observed CPR reflectivity profiles. All data files in the left column of Fig. 1 are supplied by the CloudSat data processing center in one-orbit (granule) increments. Gradient method rainfall retrievals were generally used in this study except for the warm rain periods over ocean with $R<0.5 \mathrm{~mm} \mathrm{~h}^{-1}$, when the uncertainty of this method retrieval is relatively high, so PIA-based retrievals were used. While $R$ retrievals are also available from passive AMSR-E measurements, they were not used here (except for the comparison purpose) because of differing resolutions between CloudSat and passive retrievals, the lack of coincident quantitative information on ice phase clouds from Aqua, and possible discontinuity of passive retrievals over land and water, which are based on different signal formation mechanisms (i.e., absorption versus scattering).

The uncertainties of the gradient method for retrieving rain rate are determined by the variability of the vertical profile of nonattenuated reflectivity, the influence of the raindrop size distribution details on the attenuation coefficient-rain-rate relation, variability of the cloud absorption, and uncertainties in multiple scattering corrections. The absolute radar calibration errors do not influence the results of this method because of the relative nature of gradient estimates. The contributions of different sources to the total rainfall retrieval uncertainty were analyzed in (Matrosov 2007, 2011). This uncertainty was estimated to be generally around $40 \%-55 \%$ (at the standard deviation level) for stratiform rainfall with rain rates $2-15 \mathrm{~mm} \mathrm{~h}^{-1}$. Somewhat higher errors can be expected for lighter rains with $R$ values, which are less than about $1-2 \mathrm{~mm} \mathrm{~h}^{-1}$. 
Especially high uncertainties (up to a factor of 2) could be expected for very light rainfall $\left(<0.5 \mathrm{~mm} \mathrm{~h}^{-1}\right)$.

Errors in estimating ice water content from radar reflectivity measurements are caused by the variability of the particle size distributions, uncertainties in particle shape and density assumptions, and errors in the absolute radar calibration. While total IWC (and, hence, IWP) retrieval errors for estimates in ice-dominated regions of precipitating systems can be as high as a factor of 2 (Matrosov 2011), it is not unusual for the radar-reflectivitybased methods of cloud remote sensing.

\section{CloudSat observations of an atmospheric river near its landfall}

A pronounced AR event occurred on 24-25 December 2006. Figure 2 [courtesy of Colorado State University's National Aeronautics and Space Administration (NASA) Making Earth Science Data Records for Use in Research Environments (MEaSUREs) rainfall project] shows composite maps of total precipitable water estimates (i.e., IWV) retrieved from AMSR-E data over ocean. The descending orbit measurements in the vicinity of the West Coast of North America correspond to morning satellite overpasses (10-11 UTC) and ascending orbit measurements correspond to afternoon overpasses (2122 UTC). The atmospheric river with IWV values of around $20-40 \mathrm{~mm}$ is clearly seen in this figure as it extends from tropical areas near Hawaii and reaches the Pacific Northwest and northern California on 25 December 2006. The approximate area of landfall is between latitudes $40^{\circ}$ and $43^{\circ} \mathrm{N}$.

CloudSat made two overpasses in the vicinity of the AR landfall on 25 December 2006. These overpasses are shown in Fig. 3. They approximately correspond to two vertical cross sections of the atmospheric river: one just offshore (i.e., the ascending orbit overpass) and the other a short distance inland. It is instructive to analyze CloudSat-based estimates of rainfall and ice cloud mass during these overpasses and compare CPR observations with available measurements from ground-based measurements. These measurements include rainfall estimates from the S-band ( $\sim 3 \mathrm{GHz})$ Weather Surveillance Radar-1988 Doppler (WSR-88D) network and radiosonde soundings. The NOAA HMT instrumented sites are located generally to the south of $39^{\circ} \mathrm{N}$ and in Washington State, so the coastal areas of interest to this study are covered primarily by the routine weather service observations.

\section{a. CloudSat observations of AR near the landfall on the ascending orbit}

For the event of 24-25 December 2006, the CloudSat crossing of the atmospheric river just offshore on the
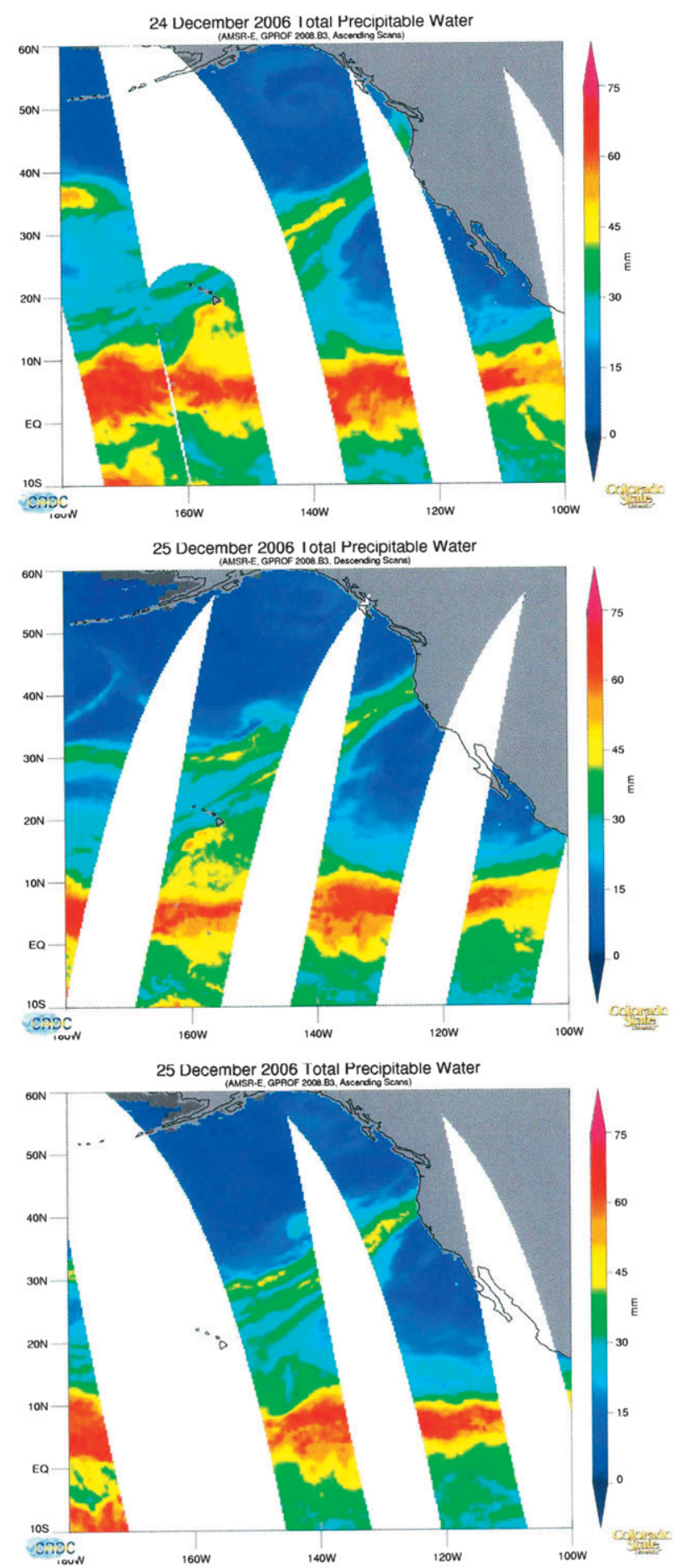

FIG. 2. Aqua AMSR-E retrievals of total precipitable water during (top) the ascending orbit on 24 Dec 2006 and (middle) descending and (bottom) ascending orbits on 25 Dec 2006. Figure courtesy of CSU's NASA MEASURES rainfall project.

ascending orbit occurred at about 2134 UTC (Fig. 2, bottom panel) almost perpendicular to the main AR flow. In the area of elevated IWV values (i.e., between 


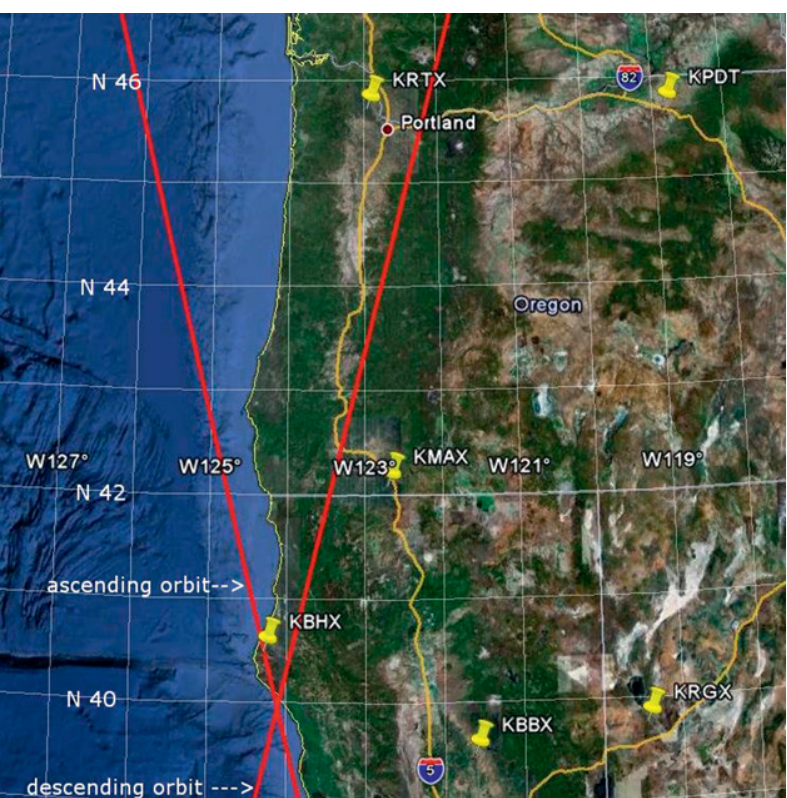

FIG. 3. CloudSat descending ( 1028 UTC) and ascending ( $\sim 2133$ UTC) orbits coincident with the landfalling atmospheric river on 25 Dec 2006. Locations of the WSR-88D radars are shown by yellow pins.

about $40^{\circ}$ and $43^{\circ} \mathrm{N}$ ), the satellite passed over the ocean (within $0-35 \mathrm{~km}$ from the coast) along the coastline (except when briefly passing a few kilometers inland between $40.1^{\circ}$ and $40.6^{\circ} \mathrm{N}$ ). Figure 4 shows the timeheight cross section of the CPR measurements during the AR crossing. The thick gray line indicates the surface elevation when the satellite crossed over land. As can be seen from Fig. 4, the surface returns leak in the first several CPR resolution gates (gate spacing is about $0.24 \mathrm{~km}$ ), making atmospheric retrievals impossible directly near the ground.

It can be seen from Fig. 4 that the cloud-top heights in the AR core vary between about 9 and $11 \mathrm{~km}$ above mean sea level (MSL). BB features and rainfall are generally present between $40.1^{\circ}$ and $43.3^{\circ} \mathrm{N}$ as manifested by the reflectivity maxima and vertical gradients. The thin black line denotes the height of the reflectivity maxima along the satellite track, which approximately (i.e., typically lower by a few hundred meters) corresponds to the freezing level (i.e., $0^{\circ} \mathrm{C}$ isotherm) height (e.g., Sassen et al. 2007; Matrosov 2008). It can be seen that this level is relatively steady between $40.1^{\circ}$ and $41.8^{\circ} \mathrm{N}$ at about $2.4 \mathrm{~km}$ MSL and then it rapidly dips to about 1.4-1.5 km MSL over the course of $0.6^{\circ}$ latitude $(\sim 70 \mathrm{~km})$. The gray line in Fig. 4 shows the $0^{\circ} \mathrm{C}$ isotherm height as estimated by the ECMWF model. While the ECMWF data agree reasonably well with CloudSat estimates between about $41^{\circ}$ and $42^{\circ} \mathrm{N}$, the model data

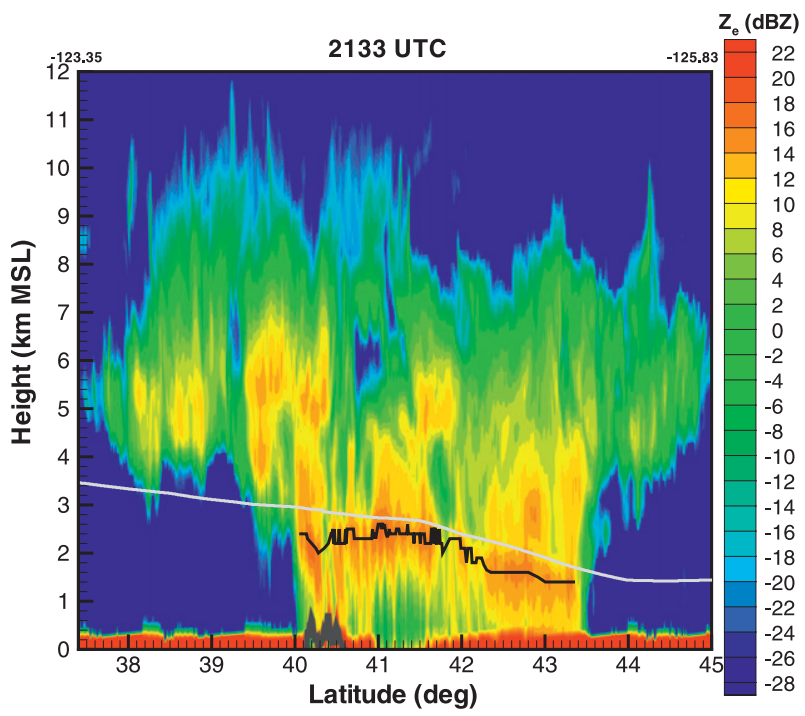

FIG. 4. CloudSat CPR reflectivity cross section of the landfalling AR just offshore at 2133 UTC on 25 Dec 2006. The BB maxima and surface elevations are shown by thin black and thick gray lines, respectively. A light gray line shows the ECMWF model freezinglevel estimates.

somewhat fail to predict the sharpness of the freezinglevel dip immediately to the north of $42^{\circ} \mathrm{N}$ (which might be, in part, due to model resolution issues), and there is some model overestimation of this level in other intervals (e.g., between $40^{\circ}$ and $41^{\circ} \mathrm{N}$ and near $42.5^{\circ} \mathrm{N}$, where difference can be as high as $0.7-0.8 \mathrm{~km}$ ).

During the overpass, CloudSat flew approximately (i.e., within a few kilometers) over the Point Arena WSR-88D radar, which has the four-letter identifier KBHX. Figure 5 shows the KBHX lowest elevation tilt $\left(\sim 0.45^{\circ}\right)$ measurements, which are closest in time to this overpass. Area of enhanced KBHX reflectivity along the CloudSat ground track indicates that precipitation is observed to the north of about $40^{\circ} \mathrm{N}$. CPR-based retrievals of mean rain rate in the layer below the freezing layer, which is not affected by the melting layer, and ground radar returns along with estimates of cloud IWP are shown in Fig. 6.

Besides rain-rate estimates, Fig. 6 also shows CloudSatbased retrievals of IWP and quasi-simultaneous AMSR-E (http://nsidc.org/data/amsre/) estimates of IWV from the radiometer resolution pixel closest to the CloudSat overpass. IWV estimates are available from pixels that do not contain land surfaces, thus the data in the interval approximately between $39.7^{\circ}$ and $41^{\circ} \mathrm{N}$ are not available. In the area of precipitation, AMSR-E estimates of IWV exceeded $20 \mathrm{~mm}$ while the peak values were reaching $44 \mathrm{~mm}$. CloudSat retrievals of total ice mass above rainfall area indicate IWP values generally between 1 and $7 \mathrm{~mm}$ 


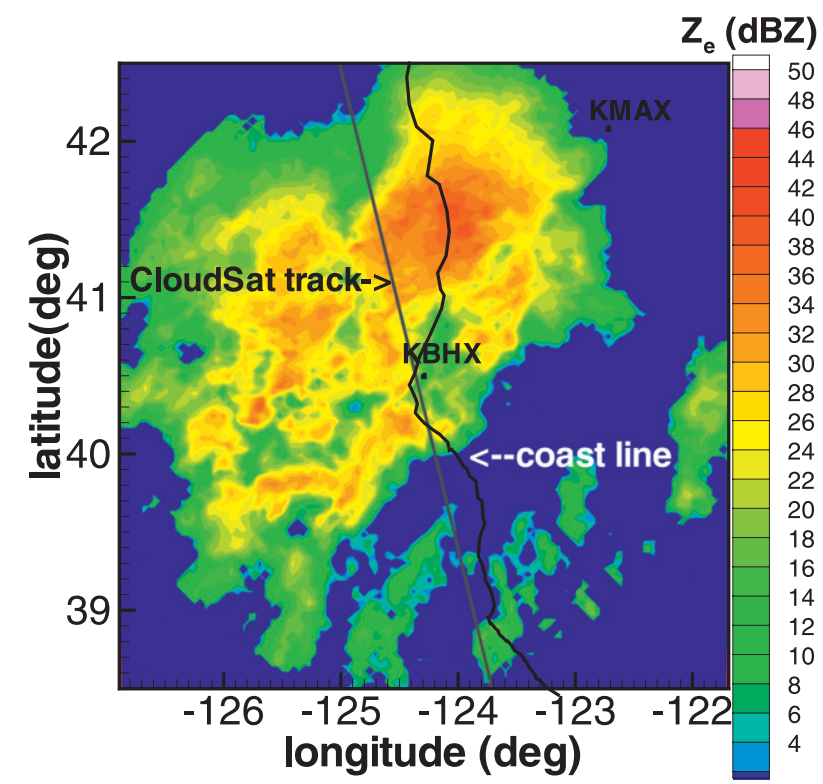

FIG. 5. WSR-88D KBHX radar measurements during measurements during the CloudSat overpass at 2133 UTC on 25 Dec 2006.

$\left(10^{3}-7 \times 10^{3} \mathrm{~g} \mathrm{~m}^{-2}\right)$. IWP values quickly fall off to the north of $43.3^{\circ} \mathrm{N}$ while AMSR-E IWV estimates decrease much more gradually.

Comparisons of rain rates from CloudSat and KBHX are of particular interest because WSR-88D data in this area are one of the main sources of high-resolution quantitative precipitation estimations (QPE). S-band signals are practically not attenuated in light-to-moderate rainfall, so the default WSR-88D reflectivity-rain-rate relation (i.e., $Z_{\mathrm{es}}=300 R^{1.4}$, where $Z_{\mathrm{es}}$ is measured WSR-88D reflectivity in $\mathrm{mm}^{6} \mathrm{~m}^{-3}$ and $R$ is in $\mathrm{mm} \mathrm{h}^{-1}$ ) was used for ground-based radar estimates. Uncertainties of QPE based on $Z_{\mathrm{es}}-R$ relations are comparable to those derived from CloudSat measurements. Comparisons between gauge-derived QPE and the WSR-88D reflectivity-based estimates indicated that while ground radar data on average provide reasonable accumulation totals, corresponding differences for individual storms can be as high as about a factor of 2 or so (Krajewski et al. 2010). Absolute reflectivity-based estimates of instantaneous rain rate are likely to have higher uncertainties than estimates of total storm accumulations.

As Fig. 6 shows, KBHX and CloudSat estimates of rain rate agree generally satisfactorily except in the area to the north of about $41.4^{\circ} \mathrm{N}$. This disagreement is likely due to the fact that the KBHX radar beam already "overshoots" the rainfall area at the corresponding radar ranges $(>\sim 100 \mathrm{~km})$ and hence WSR-88D data are not directly representative of rainfall. Accounting for earth's nonsphericity, radio-wave refraction and the

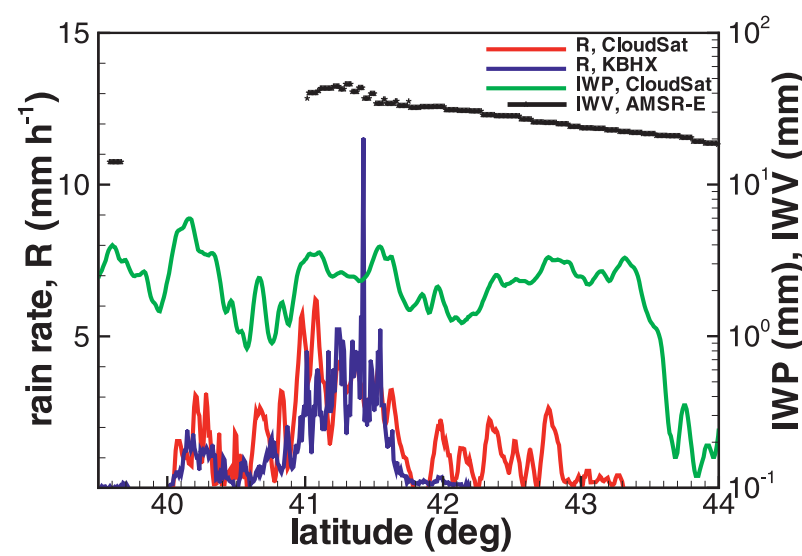

FIG. 6. Results of CloudSat retrievals of rain rate $R$ and cloud IWP (25 Dec 2006, 2133 UTC). Collocated estimates of IWV from AMSR-E and rain rates from the KBHX WSR-88D using the lowest tilt data are also shown.

altitude of the KBHX radar site $(\sim 0.73 \mathrm{~km})$ indicates that, at ranges greater than about $100 \mathrm{~km}$, the KBHX radar beam is already mostly in snow region (i.e., higher than $2.4 \mathrm{~km}$ MSL for latitudes to the north of $\sim 41.5^{\circ}-$ $42^{\circ} \mathrm{N}$ ). This is the main reason why this radar does not show significant precipitation at these latitudes. For $R>$ $0.5 \mathrm{~mm} \mathrm{~h}^{-1}$, the mean relative bias between CloudSatbased rain-rate retrievals and $\mathrm{KBHX}$ estimates for the comparison interval to the south of $\sim 41.4^{\circ} \mathrm{N}$ is $29 \%$ and the corresponding relative standard deviation is $52 \%$. These values are generally within the expected uncertainties of satellite- and ground-based retrievals stated previously.

\section{b. CloudSat observations of AR near the landfall on the descending orbit}

The CloudSat descending orbit during the landfalling AR event on 25 December 2006 occurred at about 1028 UTC. The corresponding AMSR-E IWV estimates are shown in Fig. 2 (middle panel). This overpass was over land at a relatively short distance $(0 \sim 120 \mathrm{~km})$ from the coastline. As can be seen from Fig. 3, three WSR-88D radars (i.e., KBHX, KMAX, and KRTX) were in vicinity of the CloudSat ground track $(<60 \mathrm{~km})$ during this overpass. Figure 7 shows the corresponding vertical cross section of the atmospheric river system as observed by the CPR. The area of precipitation generally extends from $40^{\circ}$ to $46^{\circ} \mathrm{N}$ and is entirely over land. The southern edge of precipitation for this 1028 UTC overpass is located at approximately the same latitude $\left(\sim 40^{\circ} \mathrm{N}\right)$ as for the ascending orbit, which occurred about $11 \mathrm{~h}$ later (Fig. 4).

As in Fig. 4, the heights of CPR reflectivity BB maxima and the surface elevations are shown in Fig. 7. The 


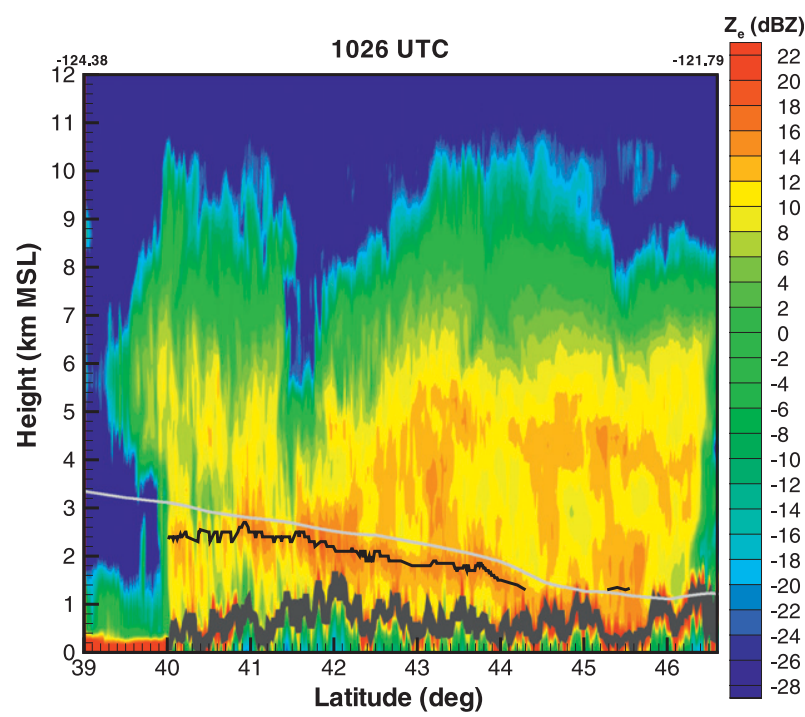

FIG. 7. CloudSat CPR reflectivity cross section of the landfalling AR inland at 1028 UTC on 25 Dec 2006. The BB maxima and surface elevations are shown by thin black and thick gray lines, respectively.

BB maxima heights during the overpass of 1028 UTC are similar to those for the 2133 UTC ascending orbit overpass. They are at about $2.4 \mathrm{~km}$ MSL for the latitude interval between $40^{\circ}$ and $41.8^{\circ} \mathrm{N}$, generally descending in the northern direction to about $1.4 \mathrm{~km}$ MSL. The BB maxima are too close to the surface between $44.3^{\circ}$ and $45.2^{\circ} \mathrm{N}$ for the CPR to identify them. Given the absence of CPR BB features there, it is likely that precipitation in this latitude interval is in the form of snow. This suggestion is also supported by the fact that no obvious signal attenuation with vertical range, which is usually observed in case of rain, is present there. Faint CPR BB features, however, are seen at about $1.4 \mathrm{~km}$ MSL in the region of lower terrain between $45.3^{\circ}$ and $45.7^{\circ} \mathrm{N}$. The ECMWF model freezing-level heights are somewhat higher than CloudSat estimates. As for the ascending orbit overpass offshore, the model data are rather smooth and they generally do not indicate relatively sharp drops in freezing-level heights (e.g., near $41.7^{\circ} \mathrm{N}$ in Fig. 7), which could be, in part, due to model resolution issues.

The appropriateness of assessing freezing-level heights using the CPR BB maxima locations can be verified independently by comparing CloudSat estimates with available data from radiosonde soundings. The Medford station $\left(42.36^{\circ} \mathrm{N}, 122.86^{\circ} \mathrm{W}\right)$ soundings yielded the height of $0^{\circ} \mathrm{C}$ level of 2.4, 2.3, and $2.2 \mathrm{~km} \mathrm{MSL}$ for 25 December 0000 UTC, 25 December 1200 UTC, and 26 December 0000 UTC, respectively. The 25 December 1200 UTC sounding is $1.5 \mathrm{~h}$ apart from the CPR measurements on the descending orbit shown in Fig. 7. These measurements indicate a BB maximum of about $2.2 \mathrm{~km}$ MSL for the orbital point at $42.36^{\circ} \mathrm{N}$, which is only $30 \mathrm{~km}$ away from the Medford station location.

The Salem sounding station $\left(44.91^{\circ} \mathrm{N}, 123.00^{\circ} \mathrm{W}\right)$ reported $0^{\circ} \mathrm{C}$ heights as $2.5,1.3$, and $1.3 \mathrm{~km}$ MSL for 25 December 0000 UTC, 25 December 1200 UTC, and 26 December 0000 UTC, respectively. While CPR measurements at $1028 \mathrm{UTC}$ near $44.91^{\circ} \mathrm{N}(\sim 45 \mathrm{~km}$ from this station) were contaminated by high terrain echoes (see Fig. 7), the available preceding and following estimates (at about $44.3^{\circ}$ and $45.3^{\circ} \mathrm{N}$, correspondingly) indicate BB maxima heights at about $1.4 \mathrm{~km}$ MSL. Overall, the agreement between CloudSat estimates of freezing level using BB maxima height and independent soundings data is good.

It is important to mention that while weather service routine radiosonde soundings along the West Coast are relatively scarce (the closest stations to the ones mentioned here are in Oakland, CA and in Quillayute, WA), CloudSat estimates are available in high resolution along the orbital track. These estimates allow observations of relatively fine details in freezing-level height trends. Such details, for example, include very rapid meridional gradients of the freezing level near latitudes $42^{\circ}$ and $43.8^{\circ} \mathrm{N}$ in Figs. 4 and 7, correspondingly.

Figure 8 depicts the three WSR-88D radar measurements for the lowest radar beam tilts $\left(\sim 0.5^{\circ}\right)$ during the CloudSat overpass shown in Fig. 7. These radars cover the area of coastal precipitation observed by CloudSat during this overpass. It can be seen from Fig. 3 that while the WSR-88D KBHX and KMAX radars are relatively close (at a distance of $\sim 220 \mathrm{~km}$ ), there is a significant gap in the weather service radar coverage between the KMAX and KRTX radars separated by a distance of about $380 \mathrm{~km}$. As for the ascending orbit discussed earlier, it is instructive to analyze the potentials of CloudSat precipitation estimates for this orbit, which approximately lies along the line connecting WSR-88D radars located inland near the coasts of northern California and Oregon.

Comparisons of CloudSat retrievals of rain rate in a liquid hydrometeor layer with simultaneous estimates from the area WSR-88D radars are shown in Fig. 9. Between $40^{\circ}$ and $41.4^{\circ} \mathrm{N}$, the agreement between satellite and the closest WSR-88D radar (KBHX) estimates is very good. CPR estimates noticeably exceed those from both KBHX and KMAX radars between $41.4^{\circ}$ and $41.8^{\circ} \mathrm{N}$. At these latitudes along the CloudSat ground track, radar beams for both WSR-88D radars (i.e., KBHX and KMAX) covering this area are mostly in the snow region, so their measurements are not directly representative of rainfall.

While CloudSat measurements show significant rainfall between latitudes $43^{\circ}$ and $44^{\circ} \mathrm{N}$, the echoes of KMAX 
25 December 2006 (1026 UTC) WSR-88D KRTX $Z_{e}(d B Z)$

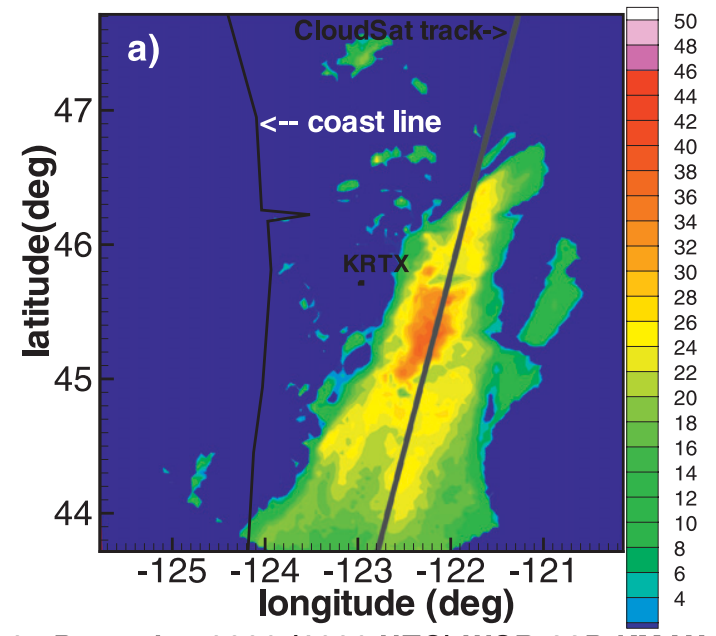

25 December 2006 (1026 UTC) WSR-88D KMAX

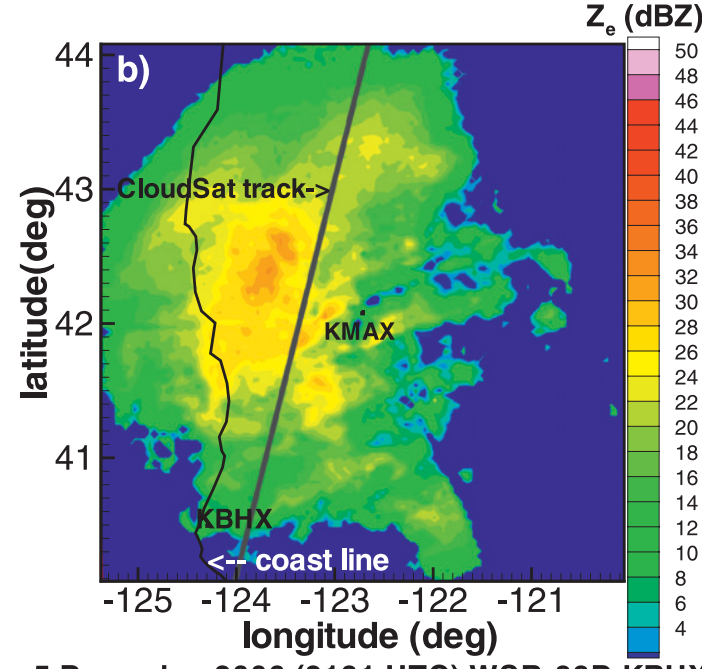

5 December 2006 (2131 UTC) WSR-88D KBHX

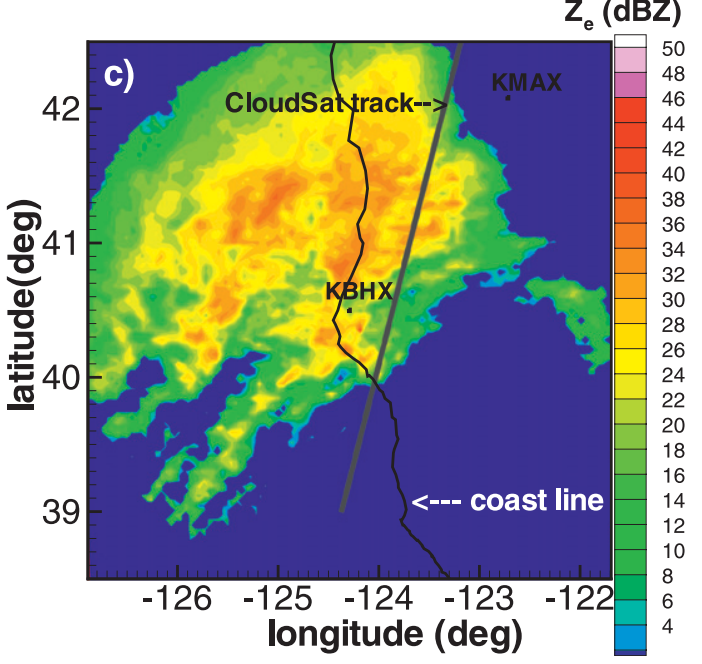

FIG. 8. (a) WSR-88D KBHX, (b) KMAX, and (c) KRTX radar measurements during the CloudSat overpass shown in Fig. 7. and KRTX radars come from areas located very high in the snow region (4-6 km MSL), where S-band radar reflectivities in stratiform rainfall systems are usually much smaller compared to rain below. Note that CPR reflectivities shown in Figs. 4 and 7 for snow regions are not representative for S-band WSR-88D reflectivities because of significant non-Rayleigh scattering effects at $\mathrm{W}$-band frequencies.

The pronounced peak in the KRTX data centered at $45.3^{\circ} \mathrm{N}$ is due to the strong S-band reflectivity region (Fig. 8a). In this region, the KRTX radar beam is centered at an altitude of about $1.35 \mathrm{~km}$, which corresponds to the melting layer as seen from Fig. 7. The melting layer S-band reflectivity enhancement could be very strong (up to $10 \mathrm{~dB}$ ), and application of the standard S-band $Z_{\mathrm{es}}-R$ relation results in overestimation of rainfall. CloudSat attenuation-based estimates of rain rate in the middle of this region are about $1 \mathrm{~mm} \mathrm{~h}^{-1}$.

Overall, accounting for atmospheric refraction and earth's nonsphericity effects indicates that, for the given estimates of the freezing-level height, WSR-88D radar measurements in Fig. 9 come from the rainfall areas only for the latitude interval between $40^{\circ}$ and $41.4^{\circ} \mathrm{N}$ (for the KBHX radar). The relative bias and relative standard deviation between CloudSat and KBHX rain-rate estimates in this interval are $24 \%$ and $49 \%$, respectively, which are within retrievals' uncertainties.

The rest of WSR-88D estimates in Fig. 9 outside the latitude interval mentioned above are influenced by echoes from the melting and dry snow regions and are not directly representative of rainfall near the surface. The $2.3-\mathrm{km}$ altitude of the KMAX radar location results in the fact that its measurements in wintertime storms very often come from regions above actual rainfall (as was the case for the considered event). Accounting for the vertical profile of reflectivity (VPR) in order to improve rainfall estimates from nonpolarimetric radars is very challenging (especially in mountainous regions) and is subject to significant uncertainties.

Unlike for WSR-88D radars, all CloudSat retrievals in Fig. 9 reflect estimates in the rainfall region. Identification of BB features (i.e., freezing-level heights) allows this region to be located. There are, however, several intervals where CloudSat rain-rate retrievals were not available because of CPR reflectivity contamination by returns from high terrain. In addition to the extended interval between $44.3^{\circ}$ and $45.2^{\circ} \mathrm{N}$ where such returns even prevented identifying BB features, rain rates could not be estimated around $41.8^{\circ}, 42^{\circ}$, $42.8^{\circ}$, and $43.5^{\circ} \mathrm{N}$. Near these latitudes, the rainfall layer above higher terrain was too thin to provide enough attenuation for application of the reflectivity gradient method. 


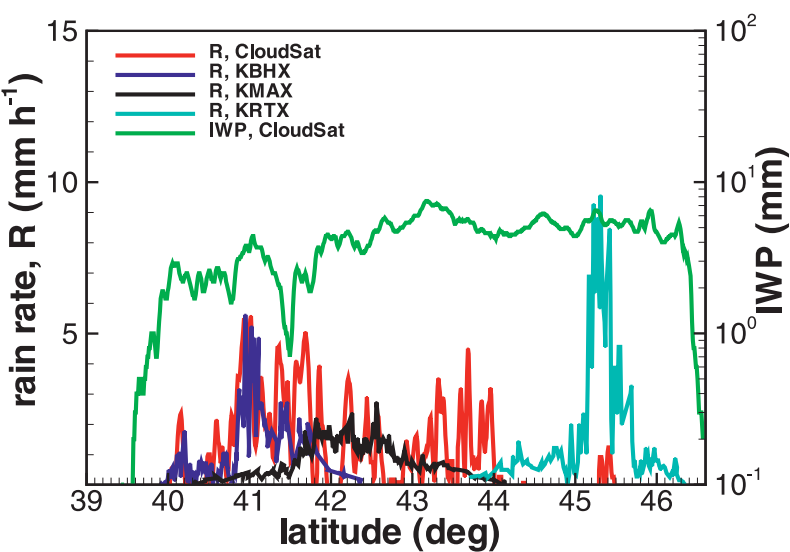

FIG. 9. Results of CloudSat retrievals of rain rate $R$ and cloud IWP (25 Dec 2006, 1026 UTC). Rain retrievals between $44.3^{\circ}$ and $45.2^{\circ} \mathrm{N}$ and near $41.8^{\circ}, 42^{\circ}, 42.8^{\circ}$, and $43.5^{\circ} \mathrm{N}$ are not available because of signal contamination by high terrain. Collocated estimates from the KBHX, KMAX, and KRTX WSR-88D radars for the lowest tilt data are also shown.

Aqua estimates of IWV over land surface for the precipitation area along the CloudSat track were not available for this overpass. The radiosonde sounding used here for verifications of CloudSat freezing-level height estimates, however, indicated IWV values in a range between 18 and $24 \mathrm{~mm}$. The CloudSat retrievals of IWP, which are also shown in Fig. 9, indicate high ice mass over the precipitation area. On average, IWP values for the inland AR crossing (Fig. 9) are higher than those for the crossing occurred near the coast over water (Fig. 6).

\section{CloudSat view of the atmospheric river cross section over open ocean}

While section 3 described the two CloudSat overpasses of the pronounced atmospheric river near its landfall on the coast of northern California and Oregon (with one overpass happening just offshore and the other one observed within a relatively short distance inland), it is interesting to analyze data from the satellite crossing of this river over the open ocean. The CloudSat satellite crossed this AR formation approximately perpendicular to the line of enhanced IWV values at around 2227 UTC on 24 December 2006. This crossing occurred between longitudes of $135^{\circ}$ and $137^{\circ} \mathrm{W}$, so the observed area was about $1000 \mathrm{~km}$ offshore. The corresponding AMSR-E IWV map is shown in Fig. 2 (top panel). Figure 10 shows the vertical cross section of CPR reflectivities during this AR crossing. As for landfall crossings, the observed precipitation in the open ocean is of the stratiform type, suggesting that snow melting processes are an important mechanism of rainfall formation there.

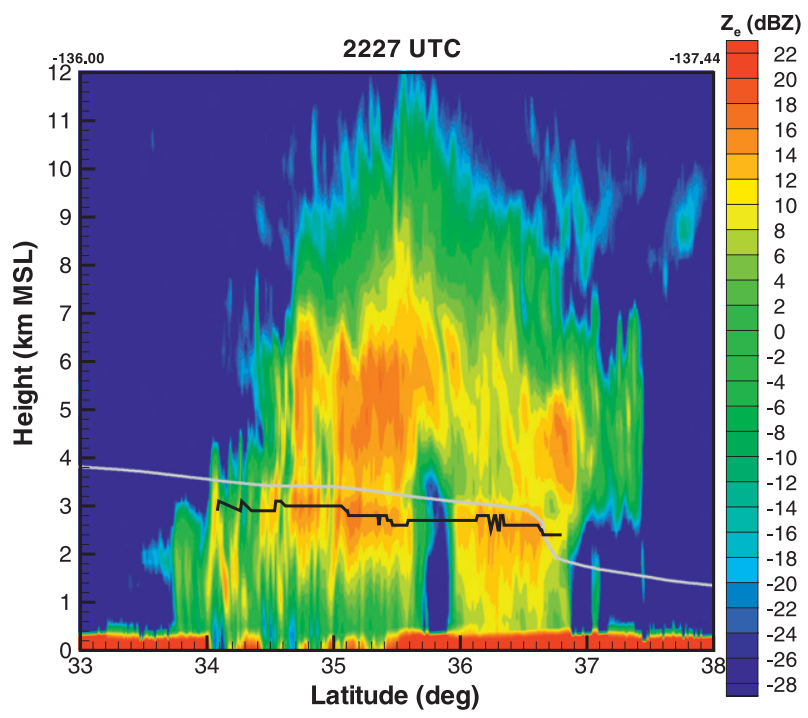

FIG. 10. CloudSat CPR reflectivity cross section of the AR over open ocean at 2227 UTC on 24 Dec 2006. The BB maxima are shown by a black line. A light gray line shows the ECMWF model freezing-level estimates.

The cloud-top heights of the precipitating system during this open-ocean crossing are similar to those observed in this AR near the landfall (i.e., $9 \sim 11 \mathrm{~km}$ MSL). The precipitation core is generally contained between $33.8^{\circ}$ and $36.8^{\circ} \mathrm{N}$ with a small clearing around $35.8^{\circ}-35.9^{\circ} \mathrm{N}$. The $\mathrm{BB}$ reflectivity maxima are quite distinct except at the very edges of the rainfall area. The freezing-level estimates from CloudSat measurements indicate the $0^{\circ} \mathrm{C}$ height at about $3 \mathrm{~km} \mathrm{MSL}$ between $34^{\circ}$ and $35^{\circ} \mathrm{N}$ and then a very gradual decrease to about $2.8 \mathrm{~km}$ MSL near the northern edge of rainfall. The observed decrease between $35^{\circ}$ and $37^{\circ} \mathrm{N}$ is generally more gradual than model estimates. The CPR signal attenuation is manifested by pronounced vertical gradients of reflectivity in the rain layer. Reflecting more substantial precipitation, the gradients are stronger in the southern part of the AR precipitation area before the rainfall gap at $35.8^{\circ} \mathrm{N}$.

Figure 11 shows CloudSat retrieval results for the oceanic crossing of the atmospheric river. Typical rain rates in the main (southern) part of the precipitation region are around $4-5 \mathrm{~mm} \mathrm{~h}^{-1}$ (except an area around $34.4^{\circ} \mathrm{N}$ ), which are similar to rain rates in the core precipitation areas for the AR landfall areas. Rainfall is significantly lighter in the northern part between about $36^{\circ}$ and $36.6^{\circ} \mathrm{N}$. IWP values above rainfall generally vary between about 1 and $11 \mathrm{~mm}\left(10^{3}-10^{4} \mathrm{~g} \mathrm{~m}^{-2}\right)$. AMSR-E-derived IWV peaks between 40 and $45 \mathrm{~mm}$ above the main precipitation region and then gradually diminishes to about $20 \mathrm{~mm}$ at $37^{\circ} \mathrm{N}$. 


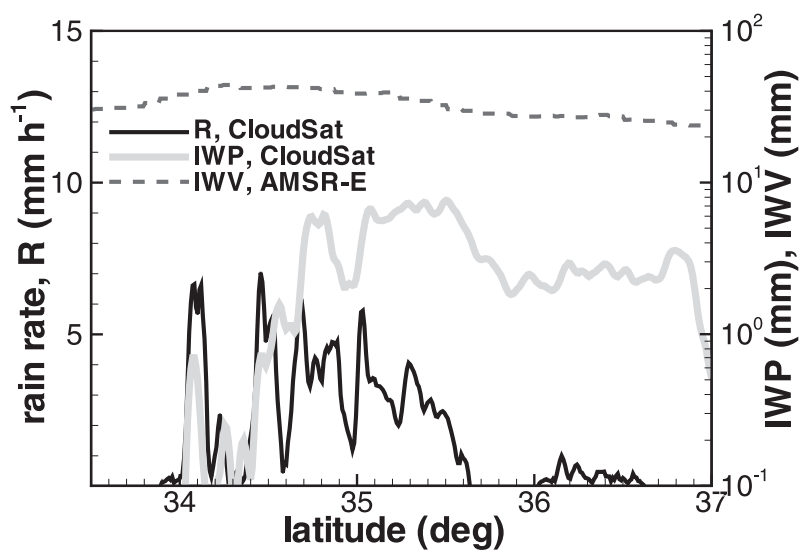

FIG. 11. Results of CloudSat retrievals of rain rate $R$ and cloud IWP (24 Dec 2006, 2227 UTC) during the open-ocean AR crossing. IWV vapor estimates from Aqua AMSR-E measurements are also shown.

\section{Case study comparisons of rainfall retrievals using other satellite approaches}

It is instructive to compare rain-rate retrievals using the CloudSat attenuation-based reflectivity gradient method employed in this study with other rainfall satellite estimates that are available over ocean. For measurements above water surfaces, the PIA method suggested by Haynes et al. (2009) is used to generate the CloudSat 2C-PRECIP-COLUMN product. Under this method, rain-rate estimates are normalized by PIA estimates obtained using radar measurements of surface returns in the presence of precipitating systems and the dataset of clear-air returns.

Satellite-borne multifrequency microwave radiometers have been used for rainfall retrievals for a number of years. AMSR-E measurements from the Aqua satellite provide radiometer-based estimates that are practically simultaneous with CloudSat retrievals. The 2C-PRECIP-COLUMN product also contains the AMSR-E rain-rate retrievals for the pixels that are closest to the CloudSat footprint. The passive retrievals use observationally constrained databases of hydrometeor and meteorological parameter profiles (Kummerow et al. 2011).

For the open-ocean AR crossing that occurred on 24 December 2006, Fig. 12 shows comparisons of rain-rate retrievals from CloudSat attenuation-based reflectivity gradient method, data from PIA-based retrievals in the 2C-PRECIP-COLUMN product, and results of the AMSR-E retrievals. The AMSR-E retrievals are for the radiometer resolution pixel, which is closest to the CloudSat radar footprint. All three types of retrievals show the bulk of rainfall confined in the latitude interval

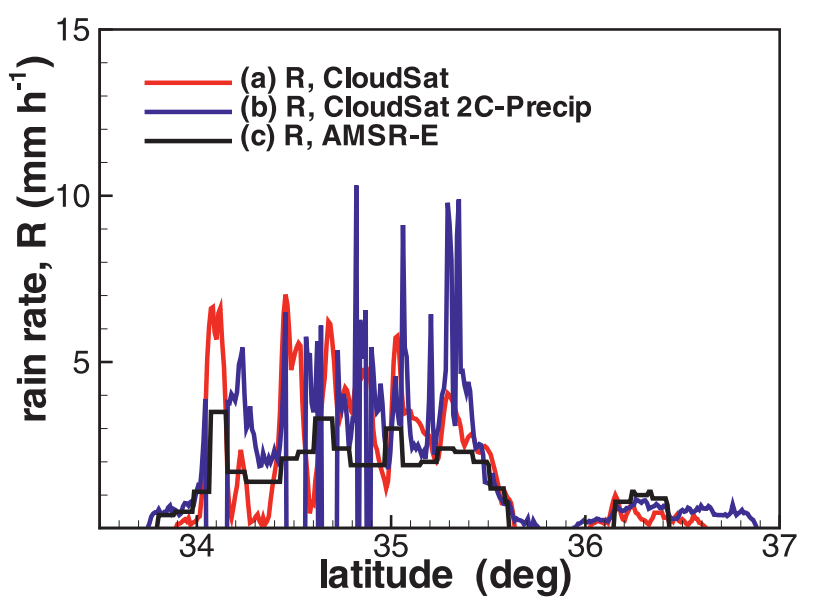

FIG. 12. Comparisons of rainfall retrievals from the (a) CloudSat reflectivity gradient, (b) PIA methods, and (c) AMSR-E multifrequency radiometer data. Note that in latitude intervals $34.05^{\circ}-$ $34.14^{\circ}, 34.46^{\circ}-34.55^{\circ}, 34.63^{\circ}-34.71^{\circ}, 34.87^{\circ}-34.88^{\circ}$, and at $34.83^{\circ}$, the surface return peak is not reliably identified (PIA $>40 \mathrm{~dB}$ ), so no retrieved rain rate is reported in the 2C-PRECIP-COLUMN product.

between $33.8^{\circ}$ and $35.6^{\circ} \mathrm{N}$. Typical rain rates there are between 2 and $5 \mathrm{~mm} \mathrm{~h}^{-1}$. All methods show that there is some light rainfall $\left(R<1 \mathrm{~mm} \mathrm{~h}^{-1}\right)$ to the north (between $36^{\circ}$ and $36.6^{\circ} \mathrm{N}$ ) of the indicated interval of main rainfall. Compared to the reflectivity gradient and AMSR-E retrievals, the PIA CloudSat method suggests that the area of this light rainfall extends farther to the north (up to $\sim 36.9^{\circ} \mathrm{N}$ ). The radar-based retrievals exhibit more variability than AMSR-E data, which, in part, could be explained by a radiometer spatial resolution that is about one order of magnitude coarser than that for the CloudSat radar.

Overall, the PIA CloudSat method provides the highest rain rates. Compared to the reflectivity gradient method, its values of $R$ are biased by about $20 \%$, and the relative standard deviation between results of these two $\mathrm{W}$-band radar-based retrievals is $52 \%$, which is generally within the retrieval uncertainties. The corresponding scatterplot is shown in Fig. 13a. The correlation coefficient between these two retrievals is 0.56 . Figures $13 \mathrm{~b}, \mathrm{c}$ show a scatterplot of AMSR-E retrievals relative to the radarbased results. Radiometer retrievals yielded on average lower rain rates. The relative biases of AMSR-E rain rates are $-27 \%$ (compared to the gradient method retrievals) and $-47 \%$ (compared to the PIA-based data in the 2CPRECIP-COLUMN product). The corresponding relative standard deviations/correlation coefficients are 58\%/0.58 and $69 \% / 0.46$, respectively. The mean rain rates in the core precipitation area were about 2.6,3.2, and $1.9 \mathrm{~mm} \mathrm{~h}^{-1}$ for the CloudSat gradient, PIA methods, and AMSR data, respectively. This region is within reach of the Tropical 


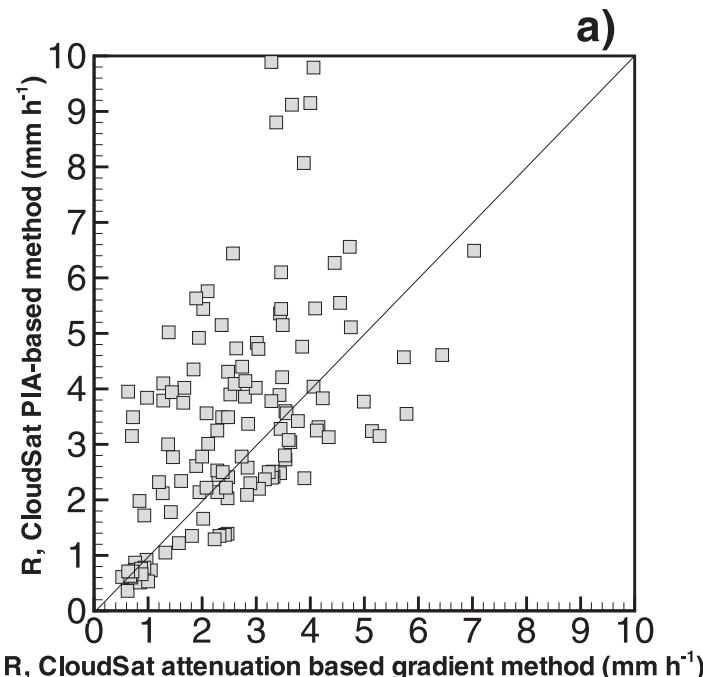

$\mathrm{R}$, CloudSat attenuation based gradient method $\left(\mathrm{mm} \mathrm{h}^{-1}\right)$

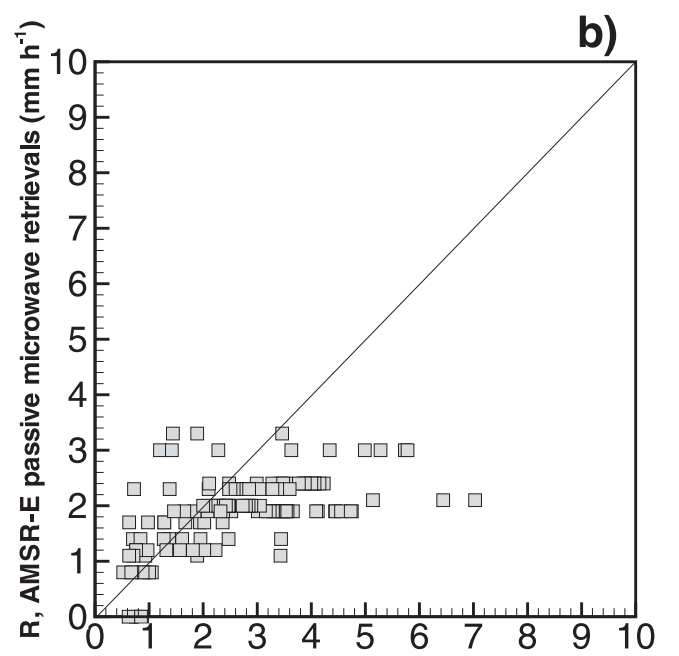

$\mathrm{R}$, CloudSat attenuation based gradient method $\left(\mathrm{mm} \mathrm{h}^{-1}\right)$

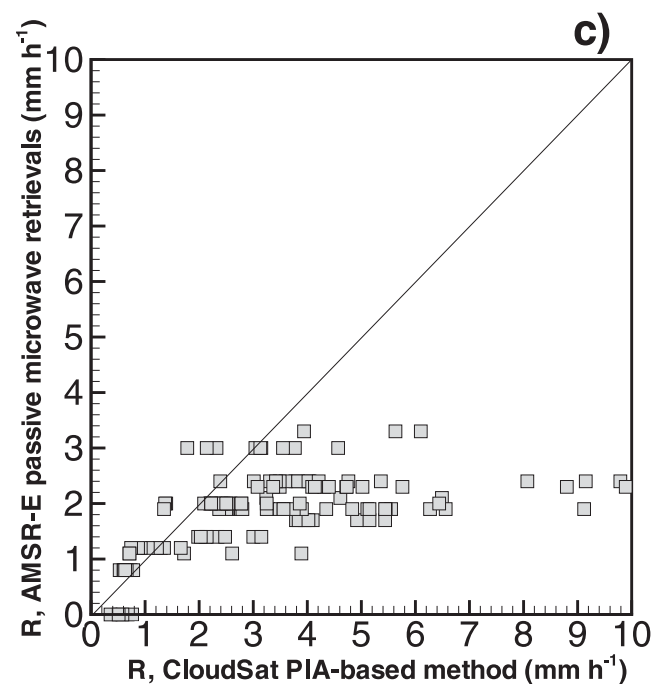

FIG. 13. Scatterplots of rain rates retrieved by different methods for the 24 Dec 2006 AR crossing ( 2227 UTC). (a) CloudSat PIAbased data vs CloudSat reflectivity gradient data, (b) AMSR-E data vs CloudSat reflectivity gradient data, and (c) AMSR-E data vs CloudSat PIA-based data.
Rainfall Measurement Mission (TRMM) satellite Ku-band precipitation radar (PR) coverage, although the A-train and TRMM satellite have different orbits, so no direct comparisons could be made. Three-hour TRMM $0.25^{\circ} \times$ $0.25^{\circ}$ products bracketing the time of the CloudSat crossing (available from http://trmm.gsfc.nasa.gov/) estimate rainfall accumulation in the vicinity of the interval in Fig. 12 between about 2.5 and $4.9 \mathrm{~mm}$.

The above-presented case studies showed the prominent AR event, which produced mostly stratiform rainfall with clear manifestation of the melting layer (i.e., $\mathrm{BB})$. Although brightband rainfall is often observed in the AR systems, warm rainfall, which does not exhibit brightband features, is also often present as part of these systems. An example of such rainfall observed by the CloudSat radar during an open-ocean crossing of a significant AR event, which impacted Southern California on 18-20 December 2010, is depicted in Fig. 14. The rainfall region during this crossing approximately extended in the interval from $28^{\circ}$ to $29^{\circ} \mathrm{N}$. Warm rainfall was observed in the southern part of this interval and mostly stratiform BB rainfall occurred in the northern part. The mean rain rate in the stratiform part of the rainfall in Fig. 14 was estimated from the CloudSat data at about $1.2 \mathrm{~mm} \mathrm{~h}^{-1}$ (not shown). The 3-h TRMM rainfall data products bracketing the time of the CloudSat crossing in this area estimate accumulation at about $2.3 \mathrm{~mm}$.

Unlike for the case of 24-25 December 2006 when CloudSat estimates within the AR crossings indicated some relatively sharp changes in freezing-level heights, which were not entirely captured by the model, there is no such changes for the 19 December 2010 crossing and the agreement between model and CloudSat estimates is good. It is instructive to compare the results of model and CloudSat estimates of the freezing level with satellite data that specifically targets temperature profiling. Since temperature profiling with IR sensors have obvious problems in the presence of hydrometeors, of interest are comparisons with microwave sounder results, which are affected by clouds and precipitation to a smaller extent. The purple dots marked by the arrows in Fig. 14 show estimates of the freezing level along the CloudSat track as obtained from the data collected by the satellite Microwave Integrated Retrieval System (MIRS). It can be seen that while some MIRS data points agree well with CloudSat and model data, others do not. There is also a noticeable variability in MIRS estimates within a relatively small interval between $28.55^{\circ}$ and $29.15^{\circ} \mathrm{N}$. In part, this variability might be attributed to cloud and precipitation affecting the quality of temperature retrievals from passive measurements. Note that MIRS estimates were not available for 2006 data. 


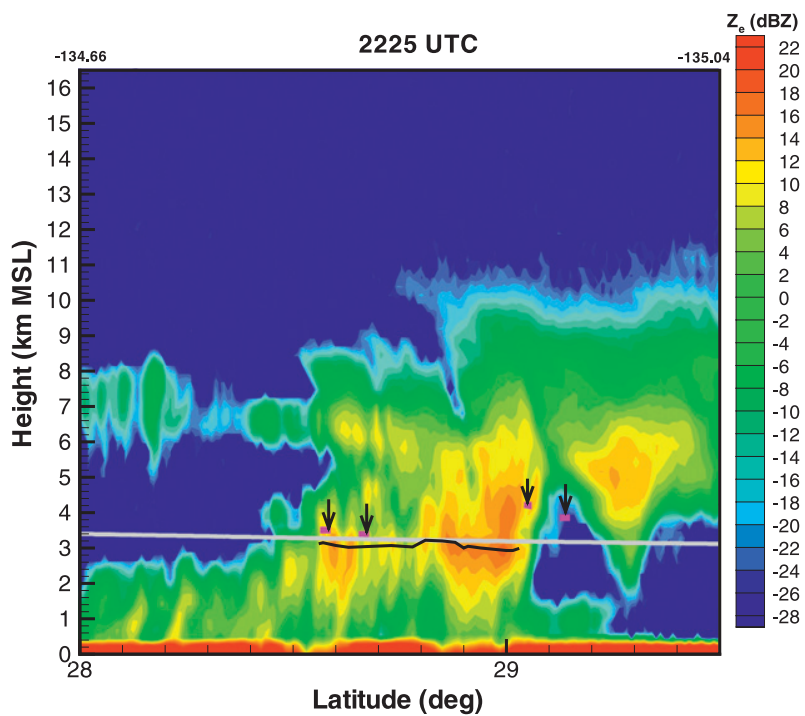

FIG. 14. CloudSat CPR reflectivity cross section of the AR over open ocean on 2225 UTC 19 Dec 2010. The BB maxima are shown by a black line. A light gray line shows the ECMWF model freezing-level estimates. Purple dots marked by arrows depict MIRS sounder estimates on 2217 UTC centered at $28.58^{\circ} \mathrm{N}$, $134.92^{\circ} \mathrm{W} ; 28.67^{\circ} \mathrm{N}, 134.41^{\circ} \mathrm{W} ; 29.05^{\circ} \mathrm{N}, 135.04^{\circ} \mathrm{W}$; and $29.14^{\circ} \mathrm{N}$, $134.54^{\circ} \mathrm{W}$

\section{Initial statistical estimates of AR properties during crossings over ocean}

While the above-presented case study results demonstrate the potential of CloudSat measurements for retrieving parameters of AR structures, the future application of described retrieval approaches to a multitude of observational cases will likely provide results that advance our understanding of these atmospheric phenomena, improving their representation in models. The primary interest area of ARs affecting the U.S. West Coast is approximately bounded by the $115^{\circ}$ and $170^{\circ} \mathrm{W}$ in the east-west direction and $55^{\circ}$ and $20^{\circ} \mathrm{N}$ in the north-south direction. As documented by the NOAA ESRL researchers (P. Neiman and G. Wick 2011, personal communication), there are typically several dozen days per a cold season when atmospheric rivers affect the U.S. West Coast. On such a day, there are typically between 1 and 4 satellite crossings of an AR over ocean in the area of interest.

It is planned that in future studies, the retrievals will be applied to a multitude of satellite crossings of atmospheric rivers occurring in the AR primary interest area during the whole period of CloudSat measurements. These future CloudSat-based AR studies will allow the addressing of some of the research theme hypotheses, which were formulated as part of the HMT-related CalWater project and state that there are significant uncertainties in model representation of ARs offshore and these uncertainties can be diagnosed through specialized observations (http://esrl.noaa.gov/psd/calwater/). CloudSat-based retrievals of AR parameters can provide observationally based statistics that could help with assessing the AR model efforts.

One example of modeling issues where CloudSat retrievals can help is differentiating between precipitation regimes (i.e., brightband stratiform rainfall versus warm rain). Since such differentiating is straightforward with radar measurements, the relative occurrence of AR warm rain can be evaluated statistically. The estimate of this occurrence as well as an occurrence of mixed rainfall (i.e., a mix of BB and warm rain) from CloudSat measurements might lead to better parameterizing cloud and precipitation microphysics in AR models as the rainfall regime prevalence was shown to be sensitive to a choice of a model microphysical parameterization scheme (Jankov et al. 2009).

In an initial attempt to provide statistical information on the rainfall regime in AR offshore, CloudSat and related observations were evaluated for the cold season of 2006/07 (i.e., October 2006-March 2007). There were overall 94 AR crossings by CloudSat during this period in the offshore area of interest when these ARs were affecting the West Coast. Precipitation cores, which were defined as the extended distance intervals along the satellite ground track within an AR system where precipitation was observed, were analyzed for these crossings (e.g., precipitation cores for the crossings shown in Figs. 4, 7,10 , and 14 are bounded between $40^{\circ}-43.5^{\circ}, 40^{\circ}-46.6^{\circ}$, $33.75^{\circ}-36.9^{\circ}$, and $28^{\circ}-29.2^{\circ}$ ). Within a precipitation core, $16 \%$ of the profiles on average did not contain rainfall, as in an example in Fig. 10, where there is rain-free interval in the vicinity of $35.8^{\circ}$.

Precipitation cores in all 94 crossings were analyzed to characterize predominant rain regimes. The warm rain regime was assigned to observed precipitating profiles if no significant amount of ice phase (IWP $<50 \mathrm{~g} \mathrm{~m}^{-2}$ ) was retrieved in the corresponding profiles. The stratiform regime was assigned to those precipitating profiles that contained a greater amount of ice. Typically those profiles were exhibiting brightband features. Often, precipitation cores consisted of both warm and stratiform rain profiles (e.g., Fig. 14). In this case, percentages of warm and stratiform rain intervals were estimated within a given "mixed" precipitation regime.

A histogram of rain type occurrences is presented in Fig. 15. The analysis indicated that about $26 \%$ and $24 \%$ of these precipitation cores were represented by predominantly stratiform rain and predominantly warm rain, respectively. The classification of predominantly stratiform rain (predominantly warm rain) implies that more 


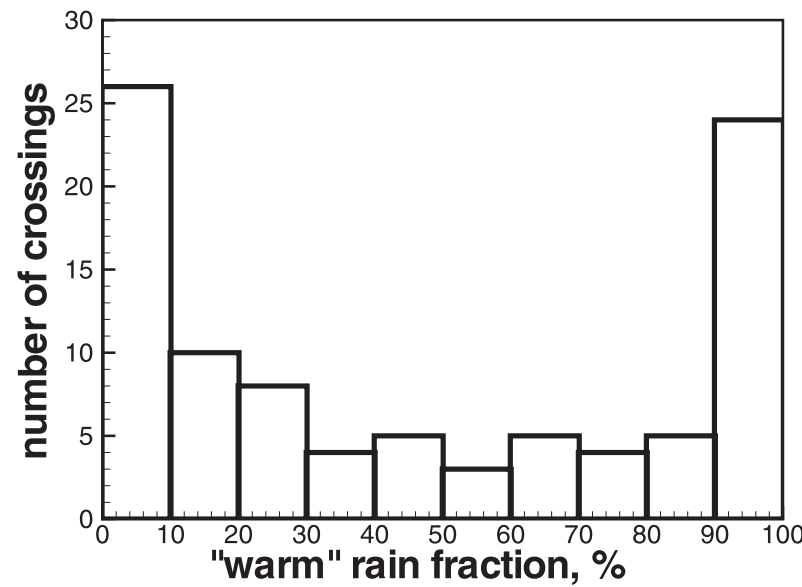

FIG. 15. Warm rain fraction of precipitation core rainfall in AR satellite crossings during the October 2006-March 2007 period.

than $90 \%$ of precipitating profiles along the ground track in the precipitation core is classified as stratiform rain (warm rain). The mean rain rate for predominantly stratiform rain was about $2.2 \mathrm{~mm} \mathrm{~h}^{-1}$. Predominant warm rain areas generally produced lighter rainfall $\left(\sim 0.5 \mathrm{~mm} \mathrm{~h}^{-1}\right)$. About half of the satellite AR crossings contained both types of rain (as in an example in Fig. 14). BB rain regions were on average more prevalent in mixed rainfall precipitation cores.

Another important AR modeling issue is water substance partitioning in BB rainfall (Jankov et al. 2009). CloudSat measurements can provide some useful observational information regarding correspondence between the rainfall and the ice phase in precipitating clouds. It can be hypothesized that some relation between these water substances exists because ice-snow melting is one of the main mechanisms for raindrop formation in stratiform BB precipitation. However, relating mean layer rain rate $R$ and IWP values retrieved simultaneously for the same atmospheric column reveals only low-to-moderate correlation $(\sim 0.32)$ between these parameters for stratiform rainfall events (e.g., Matrosov 2009). It is believed that horizontal advection and wind shear decorrelate rainfall and total ice mass (i.e., IWP) parameters for high-temporal-resolution measurements.

It can be suggested that advection and wind shear effects will be subdued if the AR crossing mean $\mathrm{IWP}_{m}$ and $R_{m}$ values are analyzed instead of instantaneous values obtained for individual CPR profiles. The availability of rainfall and total ice mass retrieval data for many crossings allows testing this suggestion. Figure 16 shows a scatterplot of mean $\mathrm{IWP}_{m}$ versus mean $R_{m}$ for the AR crossings that occurred during the cold season of 2006/07 for stratiform BB rainfall (including BB regions

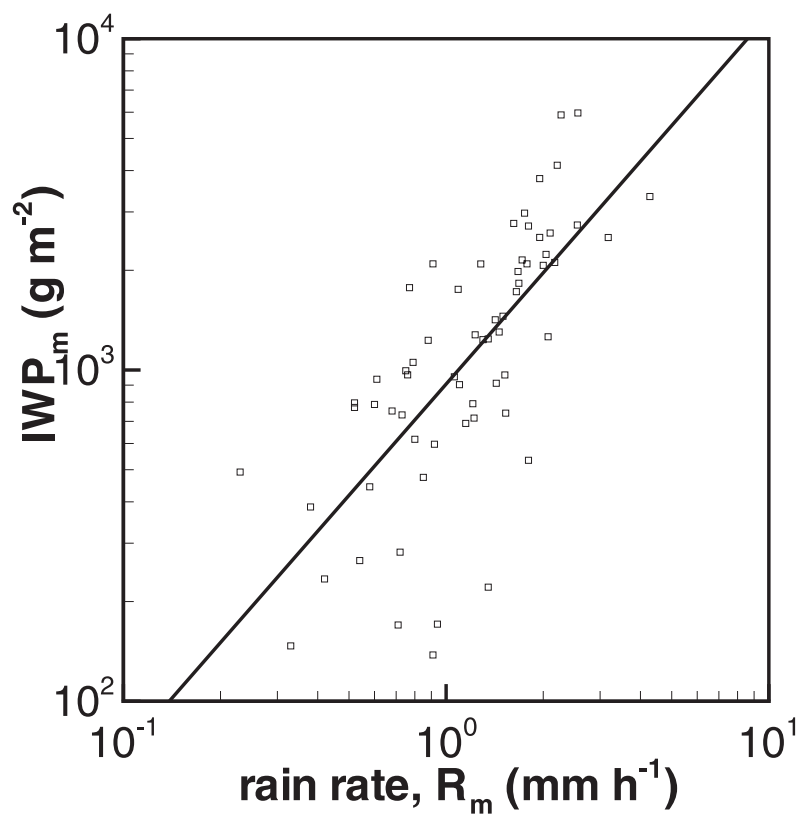

FIG. 16. Scatterplots of mean IWP and rain-rate estimates from CloudSat measurements during AR satellite crossings of stratiform $\mathrm{BB}$ rainfall regions. Data are shown for the AR crossings during the October 2006-March 2007 period.

of mixed rainfall). Each data point in this scatterplot corresponds to an individual AR crossing by CloudSat. It can be seen that there is noticeable correlation between $\mathrm{IWP}_{m}$ and resulting rainfall for BB parts of the AR systems. The best-fit power-law relation is $\operatorname{IWP}_{m}=940 R_{m}{ }^{1.07}$ and the corresponding correlation coefficient is 0.72 .

The AR CloudSat crossings above land are not as numerous as those above ocean, so multiple-year retrievals are required to get statistical properties of AR parameters. Some practical use of CloudSat AR crossings over land (especially in the areas of flood-prone watersheds) could be in BB estimates from CPR measurements, which help in discriminating rainfall from snowfall. While some specialized ground-based vertically pointing radar observations are being used for this purpose in some locations in northern California (e.g., White et al. 2010), many other areas that are affected by AR systems lack such observations.

\section{Conclusions}

In the framework of the NOAA HMT-related research, satellite measurements have been extensively used for diagnosis of the AR events that transport atmospheric water vapor from tropical regions to the midlatitudes and impact the West Coast of North America (e.g., Ralph et al. 2006). Currently, the most use is made of operational retrievals of IWV over the Pacific Ocean [e.g., from 
Special Sensor Microwave Imager (SSM/I) passive microwave measurements]. Recent studies (e.g., Wick et al. 2008; Neiman et al. 2008a) have also shown the utility of satellite-based Constellation Observing System for Meteorology, Ionosphere, and Climate (COSMIC) mission measurements for retrievals of tropospheric profiles of temperature and moisture. The imagery from geostationary satellites provides information on brightness temperatures at different spectral channels.

The CloudSat-based W-band cloud-profiling radar offers new satellite-based opportunities for observing atmospheric rivers both over the ocean and inland during their landfall, which often results in flooding. The CPR measurements provide a "quasi-instantaneous" vertical cross section of precipitating cloud systems during the CloudSat AR crossings. These measurements can be used for retrievals of rain rate and cloud IWP in the same vertical atmospheric column. While atmospheric ice estimates are generally available all the time, the rainfall retrievals can be performed using the reflectivity gradient method over both ocean and land surfaces, given that the thickness of the rainfall layer is at least $1 \mathrm{~km}$, so measurements are collected from several radar gate sampling intervals. The wintertime AR precipitation events are often of the stratiform type producing pronounced $\mathrm{BB}$ features, which provide a means for separating ice-snow and liquid phases of atmospheric hydrometeors. The warm rain areas are also often present within AR systems. PIA-based retrievals over ocean provide estimates of rain rates in such areas.

Over the ocean, cloud and precipitation retrievals along the CloudSat track can be complemented by estimates of IWV from the satellite AMSR-E microwave radiometer aboard Aqua, which flies in formation with CloudSat. The availability of simultaneous atmospheric water measurements in its three phases can provide valuable information for future investigations of atmospheric river structures. Studies of parameters of the global water cycle and their interactions in forming AR systems can also be studied in more detail with CloudSatbased retrievals of rainfall and cloud ice. The continuous measurements along the line of changing terrain could also facilitate studies of orographic effects on precipitation.

One limitation of CloudSat observations is the fact that, because of the nature of nadir-pointing CPR measurements, these retrievals are only presented along the satellite ground track, so they lack the spatial horizontal coverage provided by scanning satellite instruments. The polar-orbiting CloudSat tracks repeat themselves every 16 days, so capturing an atmospheric river landfall over a particular coastal location is in some sense haphazard. AR crossings over ocean are, however, more frequent because these crossings can happen during different orbits at various distances offshore. CloudSat observations will likely be more useful for case studies and for deriving observational relations among different AR parameters in a statistical sense rather than for real-time operational monitoring of AR events.

This paper presented observational case studies of some prominent AR events and an initial statistical analysis of CloudSat crossings of AR systems over ocean during the cold season of 2006/07. Three CloudSat AR crossings, which were analyzed in detail, occurred in the direction approximately perpendicular to the water vapor flux transport during the mature stage of the event of 24-25 December 2006. Two of these crossings occurred near the AR landfall (one just offshore and the other at a short distance inland), and one crossing happened over ocean approximately $1000 \mathrm{~km}$ from the coast. The landfall took place along the north California and Oregon coasts, which is an area with complex terrain. It lacks the relatively high-density NOAA HMT site network measurements available further to the south in central California and to the north in Washington State.

The overland crossing occurred approximately along the line connecting three coastal WSR-88D radars. Because of a combination of relatively low freezing-level heights, high altitude of some radar locations, and significant distances between WSR-88 radars, they failed to provide spatially continuous observations of rainfall that were available from the CloudSat measurements along the satellite track. Comparisons of CloudSat rainfall retrievals with WSR-88D radar estimates in the areas where these estimates were coming from regions below the freezing level showed good agreement. The differences between CloudSat and WSR-88D estimates were generally within retrieval uncertainties, which were estimated for CloudSat rainfall retrievals at about $50 \%$. Overall, CloudSat observations were able to provide rainfall information that otherwise was unavailable in this area using existing ground-based observational capabilities.

The ability of CloudSat measurements in stratiform precipitation to provide quantitative information on freezing-level heights was demonstrated. The CPR signal increase due to initial snowflake melting, followed by the rapid decrease due to attenuation in liquid and melting phase, is manifested by the reflectivity maxima located near the $0^{\circ} \mathrm{C}$ height. The altitudes of these maxima were in good agreement with freezing-level estimates using radiosonde soundings from two stations along the CloudSat ground track. CloudSat observations revealed distinct intervals of quasi-constant altitude of the freezing level and the areas of its relatively rapid changes with latitude. Such information on the freezing-level variability was 
unavailable with surface-based observations, which are sparse in this geographical region. Some rapid changes in freezing level (FL) were not well represented in the model estimates, which could be due in part to model-resolution issues. Model data could overestimate FL heights by more than $0.5-0.6 \mathrm{~km}$ compared to observations. Note that FL height uncertainties of the order $0.6 \mathrm{~km}$ can change the hydrological-model-predicted peak outflow in some watersheds by a factor of 3 (White et al. 2010). The coupled data on freezing-level heights and terrain elevations also provided information on rainfall-to-snowfall transitions in precipitation near the surface.

For retrievals over open ocean, case study comparisons of the CloudSat attenuation-based reflectivity gradient method estimates of rainfall with results of other available over-ocean retrievals from satellites indicated a general consistency of derived rain rates. Although the CloudSat radar-based estimates provided higher rain rates on average than microwave radiometer-based data, the relative standard deviations between both types of retrievals were generally within method uncertainties.

Initial statistical analysis of the $94 \mathrm{AR}$ crossings over ocean by CloudSat during the cold season of 2006/07 indicated that about $26 \%$ of rainfall occurrence in the precipitation core within an AR system corresponded to predominantly stratiform BB rainfall. Warm rain only occurred during $24 \%$ of the crossings and about half of the crossings were characterized by mixed rainfall. Relative fraction of the warm rain regions in the mixed rainfall was about $39 \%$. A significant correlation between mean values of IWP and rain rate was observed in the regions of stratiform BB rainfall. The plans for future studies include applications of described CloudSat retrievals to multiyear observations of satellite AR crossings and extending statistical analysis to other AR properties.

Acknowledgments. The author is thankful to Drs. F. M. Ralph, P. J. Neiman, G. A. Wick, and D. Jackson for useful discussions regarding the utility of CloudSat data for AR research. D. Jackson provided the MIRS data files. Drs. P. J. Neiman and G. A. Wick maintain a log of the days when ARs were affecting the West Coast. This study was funded in part by the Project NNX10AM35G and the CalWater project.

\section{REFERENCES}

Haynes, J. M., T. S. L'Ecuyer, G. L. Stephens, S. D. Miller, C. Mitrescu, N. B. Wood, and S. Tanelli, 2009: Rainfall retrieval over the ocean with spaceborne W-band radar. J. Geophys. Res., 114, D00A22, doi:10.1029/2008JD009973.

Jankov, I., J. W. Bao, P. J. Neiman, P. J. Schultz, H. Yuan, and A. B. White, 2009: Evaluation and comparisons of microphysical algorithms in ARW-WRF model simulations of atmospheric river events affecting the California coast. J. Hydrometeor., 10, 847-870.

Krajewski, W. F., G. Villarini, and J. A. Smith, 2010: Radar-rainfall uncertainties: Where are we after thirty years of effort? Bull. Amer. Meteor. Soc., 91, 87-94.

Kummerow, C. D., S. Ringerud, J. Crook, D. Randel, and W. Berg, 2011: An observationally generated a priori database for microwave rainfall retrievals. J. Atmos. Oceanic Technol., 28, $113-130$.

Matrosov, S. Y., 2007: Potential for attenuation-based estimations of rainfall rate from CloudSat. Geophys. Res. Lett., 34, L05817, doi:10.1029/2006GL029161.

- 2008: Assessment of radar signal attenuation caused by the melting hydrometeor layer. IEEE Trans. Geosci. Remote Sens., 46, 1039-1047.

_ 2009: Simultaneous estimates of cloud and rainfall parameters in the atmospheric vertical column above the Atmospheric Radiation Measurement Program southern Great Plains site. J. Geophys. Res., 114, D22201, doi:10.1029/ 2009JD012004.

_ 2010a: CloudSat studies of stratiform precipitation systems observed in the vicinity of the southern Great Plains Atmospheric Radiation Measurement site. J. Appl. Meteor. Climatol., 49, 1756-1765.

_ 2010b: Synergetic use of millimeter- and centimeter-wavelength radars for retrievals of cloud and rainfall parameters. Atmos. Chem. Phys., 10, 3321-3331, doi:10.5194/acp-10-3321-2010.

_ 2011: CloudSat measurements of landfalling hurricanes Gustav and Ike (2008). J. Geophys. Res., 116, D01203, doi:10.1029/2010JD014506.

— tinction in precipitating cloud systems from CloudSat radar measurements. J. Geophys. Res., 113, D00A05, doi:10.1029/ 2007JD009633.

_ CloudSat measurements in snow: A model study. Geophys. Res. Lett., 36, L12806, doi:10.1029/2009GL038704.

,$- \ldots$, and P. Rodriguez, 2008: Effects of multiple scattering on attenuation-based retrievals of stratiform rainfall from CloudSat. J. Atmos. Oceanic Technol., 25, 2199-2208.

Neiman, P. J., F. M. Ralph, G. A. Wick, Y.-H. Kuo, T.-K. Wee, Z. Ma, G. H. Taylor, and M. D. Dettinger, 2008a: Diagnosis of an intense atmospheric river impacting the Pacific Northwest: Storm summary and offshore vertical structure observed with COSMIC satellite retrievals. Mon. Wea. Rev., 136, 43984420.

,$--\longrightarrow$, J. Lundquist, and M. D. Dettinger, 2008b: Meteorological characteristics and overland precipitation impacts of atmospheric rivers affecting the West Coast of North America based on eight years of SSM/I satellite observations. J. Hydrometeor., 9, 22-47.

Ralph, F. M., P. J. Neiman, and G. A. Wick, 2004: Satellite and CALJET aircraft observations of atmospheric rivers over the eastern North Pacific Ocean during the winter of 1997/98. Mon. Wea. Rev., 132, 1721-1745.

,-- , and R. Rotunno, 2005: Dropsonde observations in lowlevel jets over the northeastern Pacific Ocean from CALJET1998 and PACJET-2001: Mean vertical profile and atmospheric river characteristics. Mon. Wea. Rev., 133, 889-910.

,-- G. A. Wick, S. I. Gutman, M. D. Dettinger, D. R. Cayan, and A. B. White, 2006: Flooding on California's Russian River: Role of atmospheric rivers. Geophys. Res. Lett., 33, L12801, doi:10.1029/2006GL026689. 
Sassen, K., S. Y. Matrosov, and J. Campbell, 2007: CloudSat spaceborne $94 \mathrm{GHz}$ radar bright bands in the melting layer: An attenuation-driven upside-down lidar analog. Geophys. Res. Lett., 34, L16818, doi:10.1029/2007GL030291.

Tanelli, S., S. L. Durden, E. Im, K. S. Pak, D. Reinke, P. Partain, R. Marchand, and J. Haynes, 2008: CloudSat's cloud profiling radar after 2 years in orbit: Performance, external calibration, and processing. IEEE Trans. Geosci. Remote Sens., 46, 35603573 .
White, A. B., D. J. Gottas, A. F. Henkel, P. J. Neiman, F. M. Ralph, and S. I. Gutman, 2010: Developing a performance measure for snow-level forecasts. J. Hydrometeor., 11, 739-753.

Wick, G. A., Y.-H. Kuo, F. M. Ralph, T.-K. Wee, and P. J. Neiman, 2008: Intercomparison of integrated water vapor retrievals from SSM/I and COSMIC. Geophys. Res. Lett., 35, L21805, doi:10.1029/2008GL035126.

Zhu, Y., and R. E. Newell, 1998: A proposed algorithm for moisture fluxes from atmospheric rivers. Mon. Wea. Rev., 126, 725-735. 